\title{
Rice Husk Biochar Influences Seedling Emergence of Junglerice (Echinochloa colona) and Herbicide Efficacy
}

\author{
Bhagirath S. Chauhan \\ Crop and Environmental Sciences Division, International Rice Research Institute, Los Baños, Philippines. \\ Email: b.chauhan@irri.org
}

Received April $3^{\text {rd }}, 2013$; revised May $4^{\text {th }}, 2013$; accepted June $1^{\text {st }}, 2013$

Copyright (C) 2013 Bhagirath S. Chauhan. This is an open access article distributed under the Creative Commons Attribution License, which permits unrestricted use, distribution, and reproduction in any medium, provided the original work is properly cited.

\begin{abstract}
The use of carbonized rice husk biochar improves the fertility and productivity of poor soils in rice-based cropping systems. However, biochar may also influence weed seedling emergence and the efficacy of soil-applied herbicides. Experiments were conducted in a screenhouse to evaluate the effect of biochar rates $\left(0,20,40\right.$, and $\left.80 \mathrm{t} \cdot \mathrm{ha}^{-1}\right)$ and seed burial depth $(0,1$, and $2 \mathrm{~cm})$ on seedling emergence of junglerice (Echinochloa colona) and the effect of biochar rates and pendimethalin $\left(0,500,1000\right.$, and $1500 \mathrm{~g} \cdot \mathrm{a}$.i. $\left.\cdot \mathrm{ha}^{-1}\right)$ and pretilachlor doses $\left(0,300,600\right.$, and $\left.900 \mathrm{~g} \cdot \mathrm{a} \cdot \mathrm{i} \cdot \mathrm{ha} \mathrm{h}^{-1}\right)$ on seedling emergence and seedling biomass of junglerice. Data were analyzed using nonlinear regression. The burial depth to inhibit $50 \%$ of maximum seedling emergence was $0.76 \mathrm{~cm}$ when biochar was not added to soil and the depth increased with an increase in biochar rates for soil. Similarly, compared with the soil with no biochar, the use of bichoar increased the pretilachlor dose to inhibit $50 \%$ of maximum emergence or biomass. The pretilachlor dose to inhibit $50 \%$ of maximum biomass of junglerice was $100,130,240$, and $240 \mathrm{~g} \cdot \mathrm{ha}^{-1}$ when biochar was added at $0,20,40$, and $80 \mathrm{t} \cdot \mathrm{ha}^{-1}$. However, the efficacy of pendimethalin was not influenced by biochar rate. The results of this study suggest that rice husk biochar may increase weed seedling emergence from deeper burial depths and may decrease the efficacy of some soil-applied herbicides.
\end{abstract}

Keywords: Biochar; Emergence; Efficacy; Biomass; Rice; Asia

\section{Introduction}

Rice (Oryza sativa L.) is the most important crop in Asia and more than $90 \%$ of this crop is grown and consumed in Asia. Rice produces a considerable amount of residue (straw and husk). However, most of these residues are being burned in fields in many Asian regions (e.g., India, Sri Lanka, etc.), causing air pollution, human health problems, and considerable nutrient losses [1]. Furthermore, climate change throughout the world causes concern about rice residue management. Recently, there has been an interest among researchers to use carbonized rice husk, called biochar, as a soil amendment that can act as a carbon sink in agricultural soil and can improve soil fertility and organic matter [1,2]. In addition, biochar at high rates may increase soil water retention capacity [3]. Although biochar can increase soil fertility, it may also influence weed seedling emergence and the efficacy of soil-applied herbicides as the application of biochar de- creases soil bulk density and increases organic matter [2, 4,5].

Because of labor and water shortages, direct-seeded rice systems are increasing in many Asian countries [6-9]. In direct-seeded rice systems, weeds are an important biological constraint and pre-emergence (PRE) herbicide application is essential for controlling weeds in these systems $[6,7,10]$. The use of biochar in such systems may inhibit or stimulate weed seedling emergence. Such information, however, is not available on rice weeds. In addition, the use of biochar may have either positive or negative impacts on weed management [4]. Strong adsorption of herbicides on biochar, for example, may decrease the efficacy of a soil-applied herbicide. Weed seedling emergence and herbicide efficacy may also be influenced by the rates of biochar. Such information is not available in Asia on rice weeds.

A study was conducted to evaluate the effect of biochar (carbonized rice husk) rates on seedling emergence 
of junglerice [Echinochloa colona (L.) Link], a common rice weed, from different seeding depths and the efficacy of two PRE herbicides on the weed.

\section{Materials and Methods}

Experiments were conducted in 2012 in a screenhouse at the International Rice Research Institute, Los Baños, Philippines, to evaluate the effect of burial depth on seedling emergence of junglerice and biochar rates on the efficacy of two PRE herbicides on junglerice. The soil used in the experiments was collected from an upland rice field. The soil had sand, silt, and clay contents of $31 \%, 37 \%$, and $32 \%$, respectively. Before using it, the soil was autoclaved and passed through a 3-mm sieve. In both experiments, 25 seeds of junglerice were sown on the soil surface in plastic pots and covered with a thin layer of soil. In the first experiment, biochar was mixed with soil at $0,20(1.5 \%), 40(3 \%)$, and $80(6 \%) \mathrm{t} \cdot \mathrm{ha}^{-1}$ (calculated as soil volume to $10-\mathrm{cm}$ soil depth) and seed burial depths were 0,1 , and $2 \mathrm{~cm}$. In the second experiment, biochar rates were similar to the rates used in the first experiment. In this experiment, pretilachlor and pendimethalin were used at four doses. Pretilachlor was used at $0,300,600$, and $900 \mathrm{~g} \cdot \mathrm{a}$.i. $\cdot \mathrm{ha}^{-1}$ and pendimethalin was used at $0,500,1000$, and $1500 \mathrm{~g} \cdot$ a.i. $\cdot \mathrm{ha}^{-1}$. Herbicides were sprayed $1 \mathrm{~d}$ after sowing (DAS) using a Research Track sprayer (De Vries Manufacturing, Hollandale, MN 56045) that delivered $210 \mathrm{~L} \cdot \mathrm{ha}^{-1}$ of spray solution at a spray pressure of $140 \mathrm{kPa}$. Flat fan nozzles (Teejet E0015) were used in the sprayer. The pots were irrigated $1 \mathrm{~d}$ after herbicide spray. Thereafter, pots were irrigated daily with a sprinkler system.

In the first experiment, seedling emergence of junglerice from different seeding depths was determined at 7 , 14 , and 21 DAS. In the second experiment, seedling emergence (or survival) was determined at 21 DAS. The shoot (leaf and stem) of junglerice was dried in an oven at $70^{\circ} \mathrm{C}$ for $72 \mathrm{~h}$ to determine seedling biomass. Experiments were conducted in a randomized complete-block design with a factorial arrangement of treatments. In the first experiment, factors were biochar rates and seeding depths and factors in the second experiment were biochar rates and herbicide doses. Treatments were replicated four times and both experiments were conducted two times. The data from the two "runs" were combined for analysis because there was no interaction effect of treatment and runs. The data were analyzed using an exponential model (Sigma Plot 10.0):

$$
Y=a \times e^{-b x}
$$

where $Y$ is the seedling emergence (\%) or seedling biomass $\left(\mathrm{g} \cdot \mathrm{pot}^{-1}\right)$ at seed burial depth or herbicide dose $x, a$ is the maximum emergence or biomass, and $b$ is the slope.

\section{Results and Discussion}

\subsection{Effect of Biochar Rates and Burial Depths on Junglerice Emergence}

Seedling emergence of junglerice as a function of seed burial depths is shown in Figure 1 and parameter estimates of the fitted model are shown in Table 1. At 7 DAS, the greatest seedling emergence (a) from the soil surface was observed when biochar was added to soil at $80 \mathrm{t} \cdot \mathrm{ha}^{-1}$ (70\% emergence), whereas seedling emergence from the soil surface was $58 \%$ when biochar was not added to the soil (Figure 1 and Table 1). The burial depth $\left(x_{50}\right)$ required for $50 \%$ inhibition of maximum emergence increased with an increase in biochar rates. This burial depth, for example, was $0.57 \mathrm{~cm}$ when biochar was not added to the soil and it increased to $0.83 \mathrm{~cm}$ when biochar was added to the soil at $80 \mathrm{t} \cdot \mathrm{ha}^{-1}$ (Table 1).

At 14 DAS, seedling emergence further increased; however, the response was similar to the previous observations (Figure 1(b) and Table 1). At the final observation (21 DAS), the response of seedling emergence was

Table 1. Effect of biochar rates and seed burial depths on seedling emergence of junglerice at 7,14 , and $21 \mathrm{~d}$ after sowing. Seedling emergence data were fitted to an exponential model: $Y=a \times e^{-b x} . Y$ is the seedling emergence (\%) at seed burial depth $x, a$ is the maximum emergence, $b$ is the slope, and $x_{50}$ is the burial depth $(\mathrm{cm})$ required to inhibit $50 \%$ of seedling emergence. Parameter estimates are followed by standard error in parentheses.

\begin{tabular}{ccccc}
\hline $\begin{array}{c}\text { Biochar rates } \\
\mathrm{t} \cdot \mathrm{ha}^{-1}\end{array}$ & $a$ & $b$ & $R^{2}$ & $x_{50}(\mathrm{~cm})$ \\
\hline \multicolumn{5}{c}{7 days after sowing } \\
0 & $57.7(2.1)$ & $1.20(0.11)$ & 0.99 & 0.57 \\
20 & $63.2(2.3)$ & $1.14(0.10)$ & 0.99 & 0.61 \\
40 & $65.6(1.3)$ & $1.08(0.05)$ & 0.99 & 0.64 \\
80 & $70.4(6.2)$ & $0.84(0.17)$ & 0.98 & 0.83 \\
& 14 days after sowing & & \\
0 & $69.1(0.6)$ & $0.99(0.02)$ & 0.99 & 0.70 \\
20 & $71.7(2.0)$ & $0.93(0.06)$ & 0.99 & 0.74 \\
40 & $76.0(3.6)$ & $0.85(0.09)$ & 0.99 & 0.81 \\
80 & $81.6(3.6)$ & $0.71(0.07)$ & 0.99 & 0.97 \\
& 21 days after sowing & & \\
0 & $71.1(0.6)$ & $0.91(0.02)$ & 0.99 & 0.76 \\
20 & $73.6(0.7)$ & $0.85(0.02)$ & 0.99 & 0.81 \\
40 & $78.8(1.6)$ & $0.72(0.03)$ & 0.99 & 0.96 \\
\hline & $83.1(2.9)$ & $0.57(0.05)$ & 0.98 & 1.21 \\
\hline
\end{tabular}




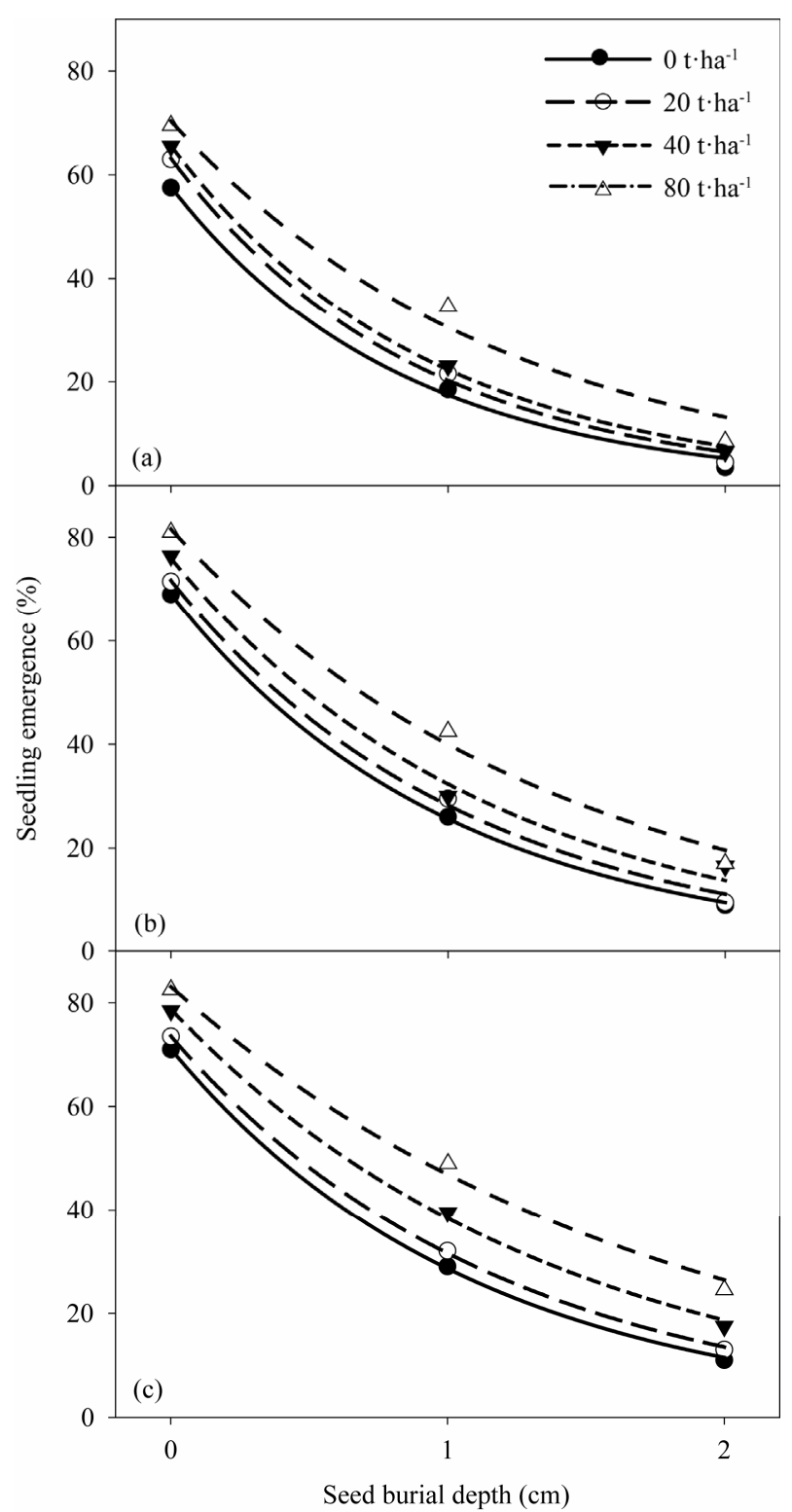

Figure 1. Effect of biochar rates $\left(\mathrm{t} \cdot \mathrm{ha}^{-1}\right)$ and seed burial depths (cm) on seedling emergence (\%) of junglerice at 7 , 14, and $21 \mathrm{~d}$ after sowing (DAS). The lines represent an exponential model fitted to the seedling emergence data. (a) 7 DAS; (b) 14 DAS; (c) 21 DAS.

consistent with the previous two observations. Maximum seedling emergence $(a)$ was $71 \%$ when biochar was not added to soil and it increased with an increase in biochar rates (Figure 1(c) and Table 1). Maximum seedling emergence was 74,79 , and $83 \%$ when biochar was added to the soil at 20,40 , and $80 \mathrm{t} \cdot \mathrm{ha}^{-1}$, respectively. The fitted model also showed that the slope $(b)$ decreased with an increase in biochar rates (Table 1).

The burial depth $\left(x_{50}\right)$ required for $50 \%$ inhibition of maximum emergence was $0.76 \mathrm{~cm}$ when biochar was not added to the soil and it increased with an increase in biochar rates. This burial depth was $0.81,0.96$, and 1.21 $\mathrm{cm}$ when biochar was added to the soil at 20, 40, and 80 $\mathrm{t} \cdot \mathrm{ha}^{-1}$, respectively (Table 1). The exponential model estimated that only $12 \%$ of the seedlings emerged from the seed burial depth of $2 \mathrm{~cm}$ when biochar was not added to the soil. When biochar was added at 20,40, and $80 \mathrm{t} \cdot \mathrm{ha}^{-1}$, seedling emergence from the 2-cm depth was $14 \%, 19 \%$, and $26 \%$, respectively.

The results of this study clearly suggest that seedling emergence of weeds from deeper depths may increase in biochar-amended soils compared with the soils to which biochar is not added. No such published information is available on weeds to compare our results; however, some information is available on seed germination of crops. Wheat (Triticum aestivum L.) seed germination increased with $10 \mathrm{t} \cdot \mathrm{ha}^{-1}$ of papermill biochar [11], whereas maize (Zea mays L.) seed germination was not significantly affected by different biochars [12]. In a recent study, wheat seed germination was stimulated at the $10 \mathrm{t} \cdot \mathrm{ha}^{-1}$ biochar (rice husk) rate but not mungbean (Vigna mungo L.) [2]. The addition of biochar to soil may improve soil fertility by increasing soil $\mathrm{pH}$, soil organic carbon, phosphorus, and potassium and this may help to stimulate seed germination [13]. However, these soil parameters were not estimated in my study. The reason for the greater emergence of junglerice from deeper depths (e.g., $2 \mathrm{~cm}$ ) with the addition of biochar could be the increased bulk density of soil, and reduced soil compaction.

\subsection{Effect of Biochar Rates and Herbicide Doses on Emergence and Biomass of Junglerice}

Irrespective of the biochar rate and pendimethalin dose, no seedling survived when pendimethalin was applied (data not shown). However, biochar rates influenced pretilachlor efficacy on junglerice. Maximum seedling emergence $(a)$ at different biochar rates was similar and ranged from 69 to 74\% (Figure 2 and Table 2). However, the slope $(b)$ of the fitted model decreased with an increase in biochar rates. The pretilachlor dose required for $50 \%$ inhibition of maximum emergence was $130 \mathrm{~g} \cdot \mathrm{ha}^{-1}$ when biochar was not added to the soil and this dose increased with an increase in biochar rates (Table 2). At 40 and $80 \mathrm{t} \cdot \mathrm{ha}^{-1}$ of biochar, the pretilachlor doses to inhibit $50 \%$ of maximum emergence were 270 and $290 \mathrm{~g} \cdot \mathrm{ha}^{-1}$, respectively. At the highest herbicide dose $\left(900 \mathrm{~g} \cdot \mathrm{ha}^{-1}\right)$, only $0.6 \%$ of the seedlings emerged when biochar was not added to the soil, whereas $7 \%$ to $9 \%$ of the seedlings emerged (or survived) when biochar was added at 40 to $80 \mathrm{t} \cdot \mathrm{ha}^{-1}$.

Maximum seedling biomass $(a)$ at different biochar rates ranged from 1.6 to $1.9 \mathrm{~g} \cdot \operatorname{pot}^{-1}$ (Figure 3 and Table 2). The slope $(b)$ of the exponential model decreased 
Table 2. Effect of biochar rates and pretilachlor doses on seedling emergence and seedling biomass of junglerice. Seedling emergence data were fitted to an exponential model: $Y=a \times e^{-b x} . Y$ is the seedling emergence (\%) or seedling biomass $\left(\mathrm{g} \cdot \operatorname{pot}^{-1}\right)$ at pretilachlor dose $x, a$ is the maximum emergence or biomass, $b$ is the slope, and $x_{50}$ is the herbicide dose $\left(\mathrm{g} \cdot \mathrm{ha}^{-1}\right)$ required to inhibit $50 \%$ of seedling emergence or seedling biomass. Parameter estimates are followed by standard error in parentheses.

\begin{tabular}{ccccc}
\hline $\begin{array}{c}\text { Biochar } \\
\text { rates }\left(\mathrm{t} \cdot \mathrm{ha}^{-1}\right)\end{array}$ & $a$ & $b$ & $R^{2}$ & $\chi_{50}\left(\mathrm{~g} \cdot \mathrm{ha}^{-1}\right)$ \\
\hline \multicolumn{5}{c}{ Seedling emergence } \\
0 & $69.1(6.0)$ & $0.0053(0.0013)$ & 0.97 & 130 \\
20 & $72.3(5.6)$ & $0.0040(0.0008)$ & 0.98 & 170 \\
40 & $72.0(5.3)$ & $0.0026(0.0004)$ & 0.97 & 270 \\
80 & $73.9(6.9)$ & $0.0024(0.0005)$ & 0.96 & 290 \\
& \multicolumn{4}{c}{ Seedling biomass } \\
0 & $1.57(0.01)$ & $0.0067(0.0002)$ & 0.99 & 100 \\
20 & $1.60(0.07)$ & $0.0053(0.0006)$ & 0.99 & 130 \\
40 & $1.69(0.11)$ & $0.0029(0.0004)$ & 0.98 & 240 \\
80 & $1.94(0.14)$ & $0.0029(0.0004)$ & 0.98 & 240 \\
\hline
\end{tabular}

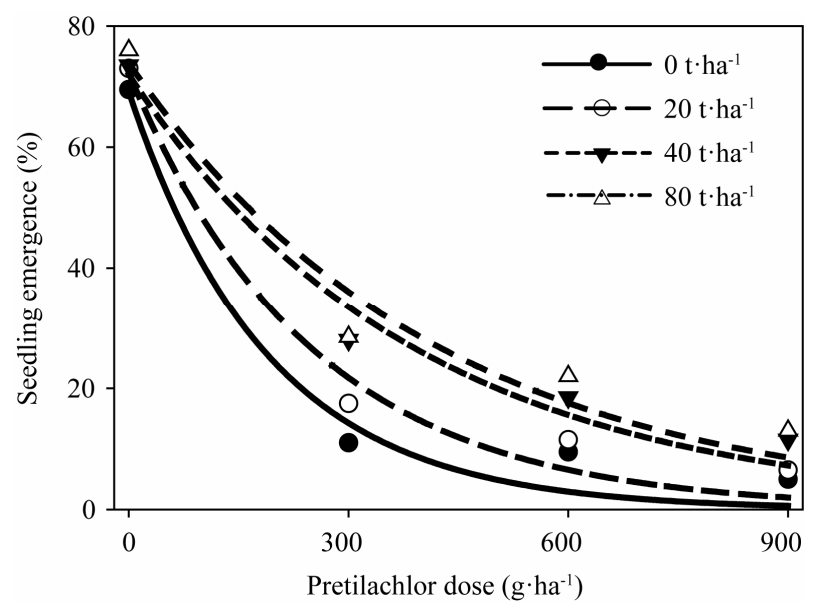

Figure 2. Effect of biochar rates $\left(t \cdot h a^{-1}\right)$ and pretilachlor doses $\left(\mathrm{g} \cdot \mathrm{ha}^{-1}\right)$ on seedling emergence $(\%)$ of junglerice. The lines represent an exponential model fitted to the seedling emergence data.

with an increase in biochar rates, suggesting that the rate of biomass reduction with increases in pretilachlor dose was slower when biochar was added to the soil. The pretilachlor dose required for $50 \%$ inhibition of maximum seedling biomass was $100 \mathrm{~g} \cdot \mathrm{ha}^{-1}$ when herbicide was applied in the absence of biochar (Table 2). However, this dose increased when herbicide was applied in the biochar-treated soil. The pretilachlor dose to inhibit $50 \%$ of maximum biomass was $240 \mathrm{~g} \cdot \mathrm{ha}^{-1}$ when biochar was

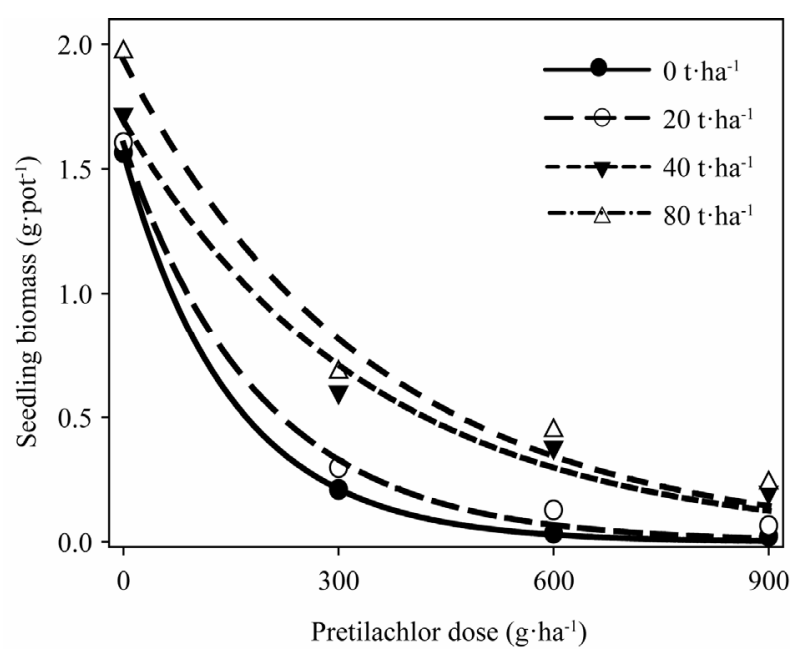

Figure 3. Effect of biochar rates $\left(t \cdot h^{-1}\right)$ and pretilachlor doses $\left(\mathrm{g} \cdot \mathrm{ha}^{-1}\right)$ on seedling biomass $\left(\mathrm{g} \cdot \mathrm{pot}^{-1}\right)$ of junglerice. The lines represent an exponential model fitted to the seedling biomass data.

added at 40 or $80 \mathrm{t} \cdot \mathrm{ha}^{-1}$. At $900 \mathrm{~g} \cdot \mathrm{ha}^{-1}$ of pretilachlor (highest dose), the biomass of surviving seedlings was only $0.0004 \mathrm{~g} \cdot \operatorname{pot}^{-1}$ in the absence of biochar. With the addition of biochar at 20,40 , and $80 \mathrm{t} \cdot \mathrm{ha}^{-1}$, however, the biomass of surviving seedlings increased to 0.0139 , 0.1245 , and $0.1445 \mathrm{~g} \cdot \operatorname{pot}^{-1}$, respectively.

In this study, the efficacy of pendimethalin was not influenced by the addition of biochar to the soil; however, biochar reduced the efficacy of pretilachlor. Pretilachlor is absorbed by roots only, whereas pendimethalin is absorbed by both roots and coleoptiles [14]. The most important absorption sites for pendimethalin in sensitive grass weeds are the coleoptiles. These observations suggest that, irrespective of the biochar rates, pendimethalin was readily absorbed by the emerging junglerice coleoptile as pendimethalin was applied on the soil surface. Organic matter in the biochar-treated soil might have bound pretilachlor and pretilachlor bioavailability to the roots of junglerice decreased, resulting in reduced efficacy in the biochar-treated soil. In a recent study, no seedlings of junglerice escaped pendimethalin when it was applied in the presence of rice residue (straw) cover [15]. However, some seedlings of barnyardgrass and rice flatsedge survived pendimethalin when it was applied in the presence of residue cover.

\subsection{Implications for Weed Management}

The addition of biochar can increase the quality, fertility, and productivity of poor soils, thereby providing an option to reduce greenhouse gas emissions and to sequester carbon in rice-based systems $[1,16]$. However, the use of biochar is not without its critics [5]. Some compounds in biochar have the potential to influence seedling emer- 
gence of crops [2] as well as weeds. In this study, junglerice emergence was greater from $2-\mathrm{cm}$ seed burial depth in the biochar-treated soil than in the soil without biochar. Similarly, the burial depth required to inhibit $50 \%$ of maximum emergence was greater when biochar was added to the soil. These results may have negative impacts on weed management. The addition of biochar may stimulate seedling emergence from deeper depths and, as seeds are present at different depths, seedling emergence may be prolonged. Because of small seed size, seedlings of some seeds, for example, Chinese sprangletop [Leptochloa chinensis (L.) Nees] and ludwigia [Ludwigia hyssopifolia (G. Don) Exell.], may not be able to emerge from a burial depth of $0.5 \mathrm{~cm}$ [17-19]. However, the addition of biochar to soils may decrease soil compaction and these weed species may easily emerge from such burial depths. There is a need to study the effect of biochar rates and seed burial depths on the seedling emergence of weeds with different seed sizes.

The high adsorption and retention capacity of biochar is not limited to nutrients only, but is exhibited toward pesticides also, including soil-applied herbicides $[4,5]$. Biochar addition to the soil can have positive or negative impacts on pest management [4]. Adsorption of herbicides can reduce leaching of soil-applied herbicides, and protect herbicides from degradation [5,20,21]. In terms of weed control, strong adsorption of soil-applied herbicides on biochar can decrease the efficacy of herbicides by influencing their bioavailability $[4,5,22]$.

Reduced herbicidal efficacy of diuron in soils amended with wheat straw biochar and clomazone in soils amended with rice straw biochar was reported in recent studies [21]. With increasing biochar in soil, higher rates of application of herbicides may be needed to achieve the same weed control as in unamended soil [21]. The results of my study, alongside those of others, also suggest that biochar may reduce the efficacy of some soil-applied herbicides.

As results were different for two herbicides, pendimethalin and pretilachlor, there was a need for further research with several soil-applied herbicides and soil types. As biochar application is predicted to rise over the next decade in response to the need to improve the fertility of poor soils, it is important that herbicide companies provide strong guidance to farmers on herbicide rates in biochar-treated soils [5]. My study and most of the previous studies were conducted on freshly prepared biochar. The long-term effect of biochar on the persistence and efficacy of herbicides deserves urgent attention.

\section{Acknowledgements}

The author would like to thank Bill Hardy, International Rice Research Institute, Philippines, for providing comments on the manuscript.

\section{REFERENCES}

[1] S. M. Haefele, C. Knoblauch, M. Gummert, Y. Konboon and S. Koyama, "Black Carbon (Biochar) in Rice-Based Systems: Characteristics and Opportunities," In: W. I. Woods, W. G. Teixeira, J. Lehmann, C. Steiner, A. WinklerPrins and L. Rebellato, Eds., Amazonian Dark Earths: Wim Sombroek's Vision, Springler Science + Business Media B.V., Berlin, 2009, pp. 445-463.

[2] Z. M. Solaiman, D. V. Murphy and L. K. Abbott, "Biochars Influence Seed Germination and Early Growth of Seedlings," Plant and Soil, Vol. 353, No. 1-2, 2012, pp. 273-287. doi:10.1007/s11104-011-1031-4

[3] J. Lehmann, "Bio-Energy in the Black," Frontiers in Ecology and the Environment, Vol. 5, No. 3, 2007, pp. 81-387. doi:10.1890/1540-9295(2007)5[381:BITB]2.0.CO;2

[4] E. R. Graber, L. Tsechansky, Z. Gerstl and B. Lew, "High Surface Area Biochar Negatively Impacts Herbicide Efficacy," Plant and Soil, Vol. 353, No. 1-2, 2012, pp. 95106. doi:10.1007/s11104-011-1012-7

[5] D. L. Jones, G. Edwards-Jones and D. V. Murphy, "Biochar Mediated Alterations in Herbicide Breakdown and Leaching in Soil," Soil Biology \& Biochemistry, Vol. 43, No. 4, 2011, pp. 804-813. doi:10.1016/j.soilbio.2010.12.015

[6] B. S. Chauhan, "Weed Ecology and Weed Management Strategies for Dry-Seeded Rice in Asia," Weed Technology, Vol. 26, No. 1, 2012, pp. 1-13. doi:10.1614/WT-D-11-00105.1

[7] B. S. Chauhan, G. Mahajan, V. Sardana, J. Timsina and M. L. Jat, "Productivity and Sustainability of the RiceWheat Cropping System in the Indo-Gangetic Plains of the Indian Subcontinent: Problems, Opportunities, and Strategies," Advances in Agronomy, Vol. 117, 2012, pp. 315-369. doi:10.1016/B978-0-12-394278-4.00006-4

[8] S. Pandey and L. Velasco, "Trends in Crop Establishment Methods in Asia and Research Issues," In: K. Toriyama, K. L. Heong and B. Hardy, Eds., Rice Is Life: Scientific Perspectives for the 21st Century, International Rice Research Institute, Los Banos, 2005, pp. 178-181.

[9] T. P. Tuong and B. A. M. Bouman, "Rice Production in Water-Scarce Environments," In: J. W. Kijne, R. Barker and D. Molden, Eds., Water Productivity in Agriculture: Limits and Opportunities for Improvements, CABI Publishing, Wallingford, 2003, pp. 53-67.

[10] B. S. Chauhan, V. P. Singh, A. Kumar and D. E. Johnson, "Relations of Rice Seeding Rates to Crop and Weed Growth in Aerobic Rice," Field Crops Research, Vol. 121, No. 1, 2011, pp. 105-115. doi:10.1016/j.fcr.2010.11.019

[11] L. Van Zwieten, S. Kimber, S. Morris, K. Y. Chan, A. Downie, J. Rust and A. Cowie, "Effects of Biochar from Slow Pyrolysis of Papermill Waste on Agronomic Performance and Soil Fertility," Plant and Soil, Vol. 327, No. 1-2, 2010, pp. 235-246. doi:10.1007/s11104-009-0050-x

[12] H. F. Free, C. R. McGill, J. S. Rowarth and M. J. Hedley, "The Effect of Biochars on Maize (Zea mays) Germina- 
tion," New Zealand Journal of Agricultural Research, Vol. 53, No. 1, 2010, pp. 1-4. doi: $10.1080 / 00288231003606039$

[13] J. M. Novak, W. J. Busscher, D. L. Laird, M. Ahmedna, D. W. Watts and M. A. S. Niandou, "Impact of Biochar Amendment on Fertility of a Southeastern Coastal Plain Soil," Soil Science, Vol. 174, No. 2, 2009, pp. 105-112. doi:10.1097/SS.0b013e3181981d9a

[14] WSSA, "Herbicide Handbook," 8th Editon, W. K. Vencill, Ed., Weed Science Society of America, Lawrence, 2002.

[15] B. S. Chauhan and S. B. Abugho, "Effect of Growth Stage on the Efficacy of Postemergence Herbicides on Four Weed Species of Direct-Seeded Rice," The Scientific World Journal, Vol. 2012, 2012, Article ID: 123071s.

[16] J. Lehmann and S. Joseph, "Biochar for Environmental Management: Science and Technology," Earthscan Ltd., London, 2009.

[17] B. S. Chauhan, "Ecology and Management of Weeds under No-Till in Southern Australia," The University of Adelaide, Adelaide, 2006.

[18] B. S. Chauhan and D. E. Johnson, "Germination Ecology of Chinese Sprangletop (Leptochloa chinensis) in the Philippines," Weed Science, Vol. 56, No. 6, 2008, pp. 820-825. doi:10.1614/WS-08-070.1

[19] B. S. Chauhan and D. E. Johnson, "Ludwigia hyssopifolia Emergence and Growth as Affected by Light, Burial Depth and Water Management," Crop Protection, Vol. 28, No. 10, 2009, pp. 887-890. doi:10.1016/j.cropro.2009.05.005

[20] H. L. Wang, K. D. Lin, Z. N. Hou, B. Richardson and J. Gan, "Sorption of the Herbicide Terbuthylazine in Two New Zealand Forest Soils Amended with Biosolids and Biochars," Journal of Soils and Sediments, Vol. 10, No. 2, 2010, pp. 283-289. doi:10.1007/s11368-009-0111-Z

[21] Y. N. Yang, G. Y. Sheng and M. S. Huang, "Bioavailability of Diuron in Soil Containing Wheat-Straw-Derived Char," Science Total Environment, Vol. 354, No. 2-3, 2006, pp. 170-178. doi:10.1016/j.scitotenv.2005.01.026

[22] X. Y. Yu, G. G. Ying and R. S. Kookana, "Reduced Plant Uptake of Pesticides with Biochar Additions to Soil," Chemosphere, Vol. 76, No. 5, 2009, pp. 665-671. doi:10.1016/i.chemosphere.2009.04.001 